\title{
Anti-Molestation: An IoT based Device for Women's Self-Security System to Avoid Unlawful Activities
}

\author{
Md. Imtiaz Hanif ${ }^{1}$ (1) , Shakil Ahmed ${ }^{2}$ (1), Wahiduzzaman Akanda ${ }^{3}$ (D), Shohag Barman ${ }^{4}$ \\ Department of Computer Science \\ American International University-Bangladesh, Dhaka-1229, Bangladesh
}

\begin{abstract}
Now-a-days, the public, mostly women and children are facing much harassment from the societies. The unlawful activities against ladies and children have been increasing significantly, and regularly we find out about eve-teasing, sexual assault cases, and attempt to molest or even killing after rape in public places or open areas. Also, many cases had gone unwarranted due to short pieces of evidence. In Bangladesh, the current statistics of sexual assaults and various unlawful activities are proliferating. To acknowledge these problems, in this paper, we have designed an IoT-based (Internet of Things) embedded device that is able to communicate with the law enforcement agency by dialing "999" (An Emergency Telephone Number in Bangladesh) on demand. The device contains Arduino Pro-Mini Microcontroller with a GSM (Global System for Mobile communication) module and can send SMS (short message service) with the victim's present area to the law enforcement agency and relatives via GPRS (General Packet Radio Services). The proposed device's form factor is too tiny to carry out easily at anywhere and anytime. The device features the "Plug \& Play" functionalities, which means one button to operate the entire device. Also, the device is costeffective so that people of every level can afford it at a reasonable price.
\end{abstract}

Keywords-Anti-rape; IoT device; smart-safety device; women safety; wearable device; GSM/GPRS

\section{INTRODUCTION}

Women reserve the option to be liberated from savagery, badgering, and segregation. Eliminating the obstructions of a hazardous domain can assist women with satisfying their potential as individuals and as supporters of work, communities, and economies. However, the World Health Organization (WHO) evaluates, about $35 \%$ of ladies worldwide have confronted either physical or possibly sexual private assistant mercilessness or non-associated sexual brutality throughout their life. Furthermore, more than 15 million young ladies matured 15-19 years have encountered rape [1]. Brutality against ladies and kids does not separate by race, religion, culture, class, or a nation. Recently, in Bangladesh, these types of unlawful activities are booming rapidly. Every morning, when we take the newspaper in hand, we find out various rape cases, killing, and molestation against women. Also, unlawful activities like kidnapping, hijacking, and robbery, etc. are happening every day. According to the statistical report of "Ain o Salish Kendra" (ASK), in 2018 to Aug. 2020 in Bangladesh, more than 3000 women were raped, and 180 women were killed after rape [2]. Among those cases, only the child rape cases were more than 600. Working ladies, female understudies, and children especially confronted this unfortunate incident.

At this moment, we can undoubtedly get to the necessary information in real-time, from (nearly) whichever area we are at. Due to rapid advancements in embedded systems, the IoT-based devices are getting popular day by day because of its flexible interactivity. IoT energizes the correspondence between gadgets. It also makes robotics easy and minimizes humanoid sweats that can save much time. Nevertheless, some security and privacy issues also are there in the IoT system [3]. So in this paper, we have designed an IoT-based device, namely, "Anti-Molestation," to ensure women and child safety in daily life. The device can send SMS with the victim's current location to her friends and family. Also, the device can make the call to "999" (Emergency Number of Bangladesh) as on-demand. We have developed the device in such a way that every level of women or people can afford it at a reasonable price. Moreover, we designed the prototype model as too small, and also it can be formed in a smaller device to use it in a locket, hand-bag, and pocket or as a bracelet, etc. So the contributions of our device are:

- It can send SMS with the current location.

- It can make a call by pressing a single button.

- The device is cost and power-efficient.

- The device overcome burst-transmission phenomenon.

The paper is formulated as six sections. In Section 2, the previous work on women's safety has been discussed. In Section 3, we have discussed our system model and the overall framework. In Section 4, the implementation details of our device has been shown. In Section 5, the overall methodology and results are discussed. Lastly, we have concluded the paper by discussing the overall summaries and the scope of future work.

\section{RELATED WORK}

By studying literature, we have come to know that many works had done to ensure women's safety by proposing various IoT and Application-based devices [4]. A.Z.M. Tahmidul et al. 5] proposed an application based wearable device. The primary function of this device is to send SMS and the victim's current area to the closest police headquarters and family members. The application interface is designed in such a way that the map indicates a safe location to survive from a criminal attack. This device is not user friendly for rural women. Many of the girls from rural areas are not familiar with mobile applications, or they may even not have a smartphone. However, the form factor of this device is too large to carry it easily. To avoid rape, another paper [6] also proposed a smart mobile application "BONITAA" which also warped with 
various features such as SMS and location sending via GSM, health supports, medical supports, counseling, self-defense tips for the rape victims. To acknowledge the problem of rural women, they integrated the "Bangla" language in their application and tried to make it user friendly. However, the problem is that the women who are not familiar with using mobile applications may not relish the facilities of those applications.

The author in [7] proposed a wearable device to ensure women's safety to avoid sexual assault. The method also introduced a mobile application. They designed their device using GSM, GPS (Global Positioning System), and the Wi-Fi (Wireless Fidelity) module integrated with a Microcontroller. The device is also able to make the call and send the location to the pre-recorded numbers or the nearest police stations to avoid unlawful activities. The main problem is that the device needs the always-on internet for web server access. They spent a lot on building such a device with a mobile application. It can not be affordable for every woman in our society, and also the application-based interface is not flexible for all end users. In the paper [8], the author also proposed a women safety device. The device also can send SMS and location to the pre-saved phone numbers. To avoid sexual manipulations, the authors integrated three push-buttons, GSM, GPS, RFID (Radio-Frequency Identification), vibrator, buzzer, and display with a Microcontroller. The main problem is that their prototype model is too large to carry. The device also contains three switches, which are very difficult to navigate through those switches in a panic situation.

U. Rai et al. [9] developed a safety device using RaspberryPi with a GPS module and a push button. When a girl presses the push button, the device sends its longitude and latitude via a GPS module. They also developed their location finder application to identify the victim's location. The prototype is simple but large in size. Raspberry-Pi needs the always-on internet to capture the location's coordinates. N. R. Sogi et al. [10] also proposed a Raspberry-Pi based IoT device. They called their device as "SMARISA" smart ring for women's safety. The device also can send the location, and additionally, it contains a camera module. When a woman presses the button, the device is activated, and the camera module captures the incident and upload images in the local-host server and generate sound with the buzzer. They also developed a mobile application to communicate with the victim's trusted one. The problem of this device is that no GSM module was not considered, and costly to develop such devices. Moreover, "Raspberry-Pi", a mini-computer, is also power-hungry. Various sensors, such as pulse rate, motion, and temperature sensor, etc. are used in [13], [14], [18]. Those devices might not work correctly because of integration of various sensors in one module. The sensors may generate wrong readings in any situation that can activate the device. The form factors of those devices are also too large to carry. Another device [11] developed to help the victims from the teaser and molester. The device also sends the SMS and current location to the family members of the victim. Sensor-based devices are not efficient to use because of its fault result generation.

T. Sen et al. [12] developed a women's safety device with Raspberry-Pi. The device contains a monumental architecture with its camera module nerve simulator. The device can send the victim's location via GPS and GSM module. The authors also developed an android application and local server to maximize women's security. Nevertheless, the problem is that the device is too big and can not be carried out easily. V. Sharma et al. [15] also developed a smart shoe to ensure women's safety. The authors used Raspberry-Pi and ArduinoUno Microcontrollers to implement their system. First of all, a shoe base video capturing devices are not efficient to capture correct frames. Besides, the use of Arduino Microcontroller rather than Raspberry-Pi is inadequate in this case. Also, the shock generation of $400 \mathrm{KV}$ can kill a human within some minutes. Another work [16] was proposed for supporting the women in danger. The device is also designed to send SMS and location to relatives of the victim. The device is too huge with its AAA size batteries and the large LCD screen. M. R. Ruman et al. [17] also developed a safety device for women's safety. The device is also able to send the location of the victim and can be rescued early. The device contains a shock generator also. Integration of various extra facilities, the prototype is too large to carry.

To acknowledge these problems, we have also built our safety device to support the women and child. The device is so tiny and can be carried out efficiently in daily life. Moreover, our device is very much cost efficient that people of all levels can afford it at a reasonable price. The device also has the feature of "Plug \& Play". So, one operational button to activate the device for all functionalities.

\section{FRAMEWORK AND SYSTEM DESIGN}

In this section, we have discussed the overall framework of our "Anti-Molestation" safety device. The framework contains two types of system design.

\section{A. Working Framework}

At first, we turn on the device, and when the system is started, it will initialize the SIM800L module. Then the GPRS and GSM module will ready to read the data from the user when we press the button once it obtains the Geo-Coordinate of the current location via GPRS. Then the system sends the HTTP (Hypertext Transfer Protocol) POST request using the "AT" attention command along with the Geo-Coordinate location to the associated application server. Then the application server sends the Geo-Coordinate location to the prestored phonebook of the victim's relatives and "999" via SMS gateway. When we long-press the panic button, the system is ready to call the pre-saved emergency phone number, or "999" on demand. Here, Fig. 1 1 illustrates the overall working framework of our proposed "Anti-Molestation" safety system. 


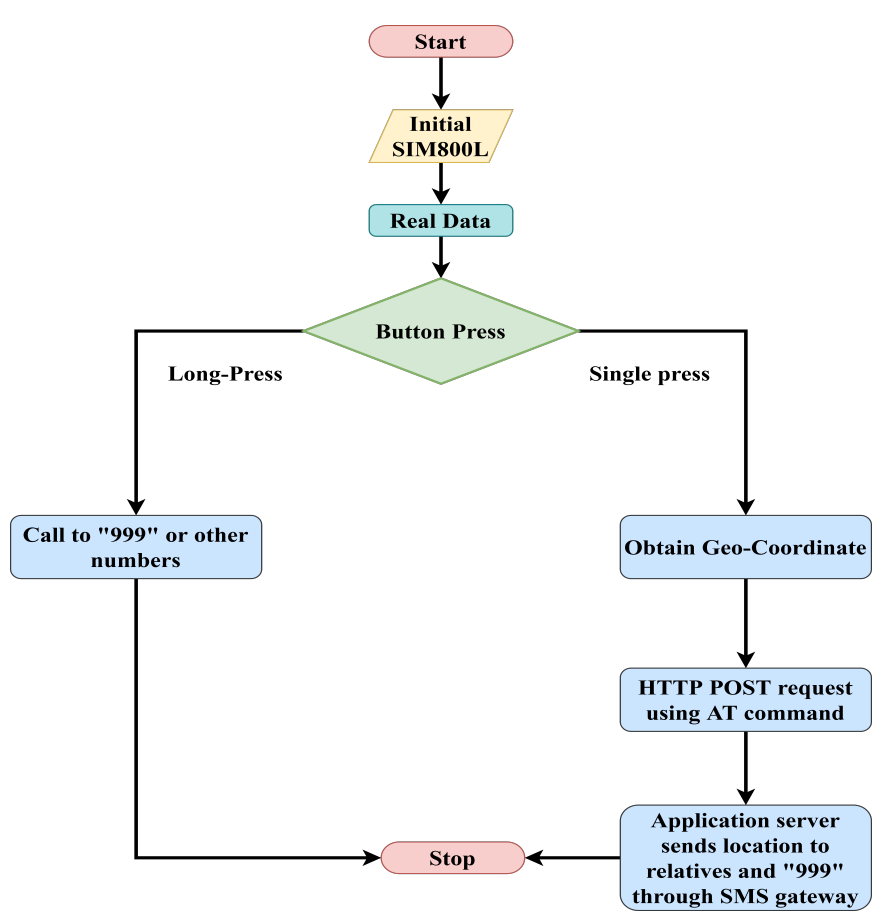

Fig. 1. The Working Framework for our Anti-Molestation Safety Device. Here, "999" is the Bangladeshi Emergency Telephone Number, and the "AT" Denotes the Attention Command to Send Location via Geo-Coordinate.

\section{B. Block Diagram and Components}

The square diagram of the framework in Fig. 2 illustrates overall hardware required for developing the gadget.

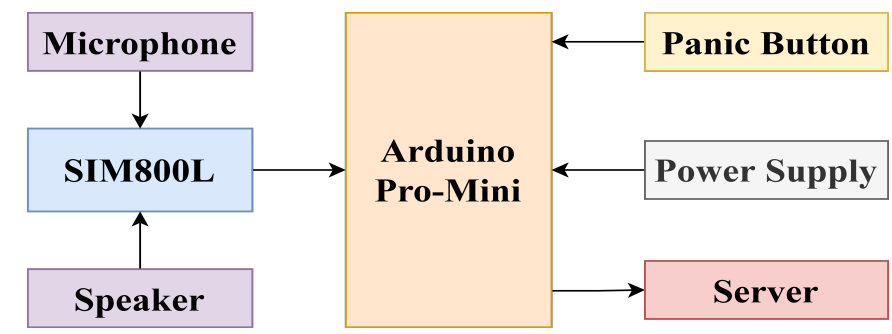

Fig. 2. The Block Diagram of our Device. The Block Diagram shows all the Hardware we have used to Develop our Safety Device.

The main heart of this device is the Arduino Pro-Mini Micro-controller to handle the entire mechanisms. A localhost server is proposed for keeping the truck of every SMS and deliver it to the adjacent police stations. A power supply is needed to power up the device. We have used Li-Poly (Lithium-Polymer) battery as a power supply. The block diagram also contains a panic button to operate the entire device. A SIM800L module has been used for taking advantage of the GPRS and GSM functionalities. We have used a condenser microphone and a speaker to communicate with the pre-saved emergency numbers. All those components are integrated with the Arduino Pro-Mini Microcontroller.

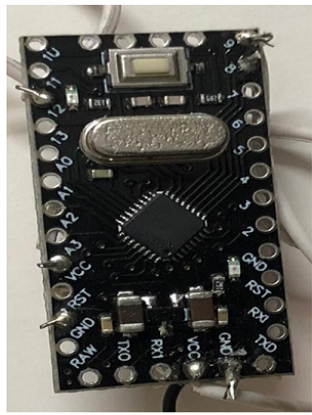

(a) Arduino Pro-Mini.

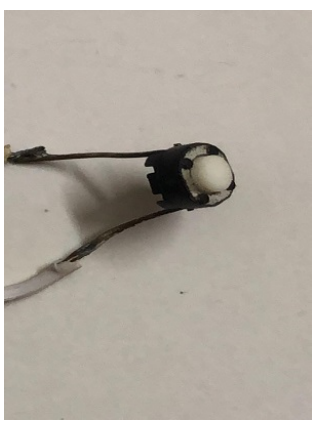

(c) Panic Button.

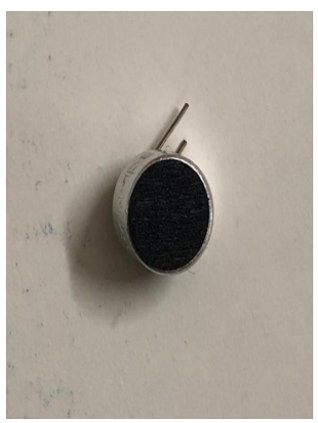

(e) Microphone.

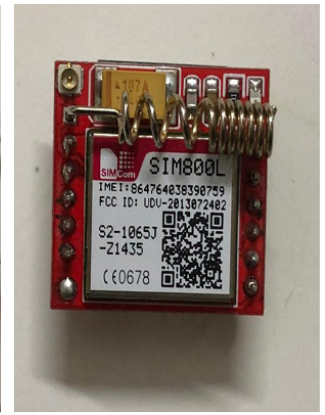

(b) SIM800L Module.

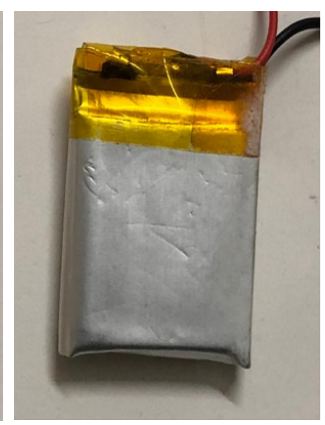

(d) $3.7 \mathrm{~V}$ Battery.

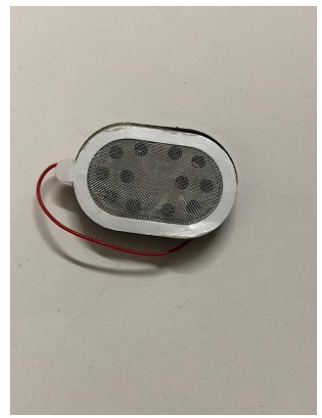

(f) Speaker

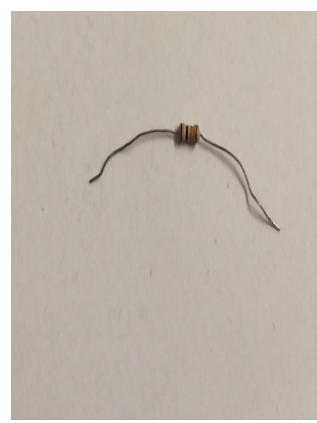

(g) Resistance.

Fig. 3. The figure shows the Necessary Components that we have used for Developing "Anti-Molestation" Safety Device.

1) Microcontroller: A Microcontroller (Fig. 3a) is a minimized incorporated circuit proposed to oversee a specific activity in a rather system. AA normal microcontroller fuses a processor, memory, and I/O (Input-Output) peripherals on a single chip. Here, we have used an Arduino Pro-Mini Microcontroller, which is too small and can handle all the 
things we need.

2) SIM800L Module: We have used SIM800L GSM/GPRS module (Fig. 3b) for calling and sending SMS functionalities. The module is attached to the Microcontroller. This module has a small form factor, and a Subscriber Identify Module (SIM) is attached to it.

3) Panic Button: We have used a panic-button (Fig. 3c) to perform "Plug \& Play" features. The panic-button regulates two functionalities like single press and long-press.

4) Power Supply: We have used a 3.7V Lithium-Polymer (Li-Poly) rechargeable battery (Fig. 3d) to power the device. We used this because of its small dimensions. Also, a charging port is included to charge the device.

5) Condenser Microphone and Speaker: We have used a condenser microphone (Fig. 3e) and a speaker (Fig. 3f) to transmit the voice through the safety device so that the law enforcement agency can hear the sounds around the prey.

6) Resistance and Some wires: We used a $10 \mathrm{~K} \Omega$ resistance (Fig. 3g) for voltage regularization. Moreover, some wires were used for making connections to the entire peripherals.

\section{IMPLEMENTATION DETAILS}

In this section, we have discussed the step by step procedure of the overall hardware implementation of our safety device. Here, Fig. 4 illustrates the circuit diagram of our safety system.

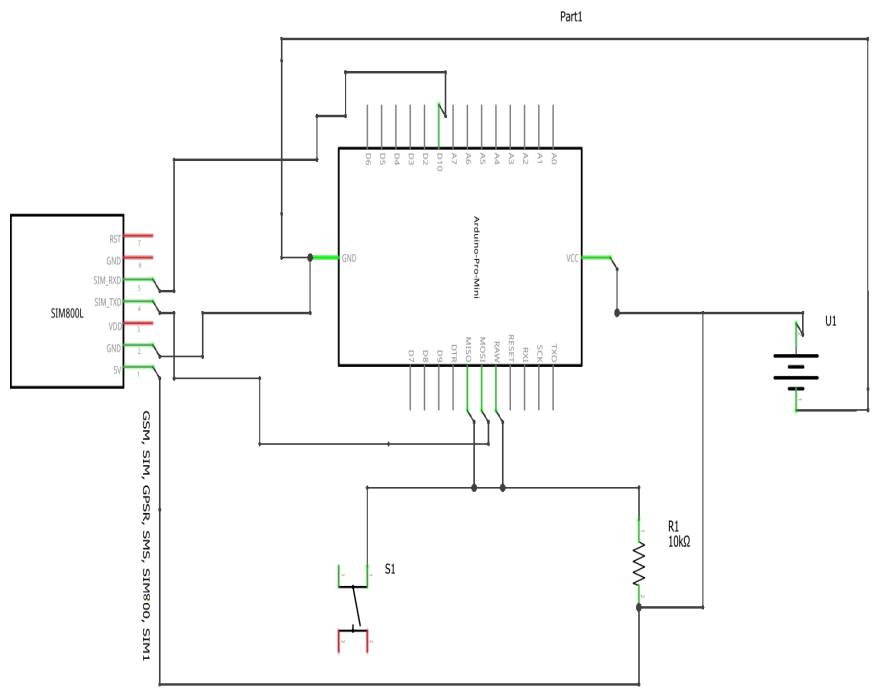

Fig. 4. The Circuit Diagram of the Device. Here, S1, R1, and U1 denotes the Switch, Resistance and Battery, Individually.

First of all, we need the Arduino Pro-Mini Microcontroller to connect all peripherals because it is the heart and only one thing that can operate all other hardware. Here, in Fig. 4, we can see that SIM800L has several pins and the SIM_RXD pin connects with Arduino's digital Input-Output (I/O) 10 pin for serial communication. The SIM_RXD is the receiver pin.
The SIM_TXD is the transmitter pin and connects with the Microcontroller's Master Out Slave In (MOSI) pin for sending data to the peripherals. We have used a rechargeable $3.7 \mathrm{~V} \mathrm{Li-}$ poly battery to power up the whole device.

TABLE I. THE COST DISTRIBUTION OF USED COMPONENTS. WE CALCULATE THE COST BOTH IN US DOLLAR AND BANGLADESHI TAKA.

\begin{tabular}{|l|l|l|}
\hline Product Name & $\begin{array}{l}\text { Price } \\
\text { (USD) }\end{array}$ & $\begin{array}{l}\text { Price } \\
\text { (BDT) }\end{array}$ \\
\hline Arduino Pro-Mini & 1.56 & 2 \\
SIM800L & 1.57 & 134 \\
Panic Button & 0.02 & 2 \\
Li-poly Battery & 1.09 & 93 \\
Condenser Mic. & 0.09 & 8 \\
Speaker & 0.02 & 2 \\
10K $\Omega$ Resistor & 0.05 & 5 \\
\hline Total (approx.) & $4.40 \mathrm{USD}$ & $377 \mathrm{BDT}$ \\
\hline
\end{tabular}

The positive wire of the battery is connected with the Microcontroller's VCC pin, and the negative wire is connected to the GND pin. The Microcontroller has the Master In Slave Out (MISO), and RAW pins are serially connected with the switch $\mathrm{S} 1$ to on-off the device. A $10 \mathrm{~K} \Omega$ resistor is also used for the voltage regulator. The SIM800L module has the MIC pin to connect the condenser microphone and the SPK pin to connect the speaker. To build this device, we have spent some money to buy the necessary components. The total cost of developing the "Anti-Molestation" safety device is approximately 400 BDT or 4.42 USD. Here, Table 1 shows the cost distribution of our necessary components.

The pictorial view of Fig. 5 illustrates the overall view of the Anti-Molestation safety device. Fig. 5a shows the dissection view of the entire device and Fig. $5 b$ shows the developed view of the device.

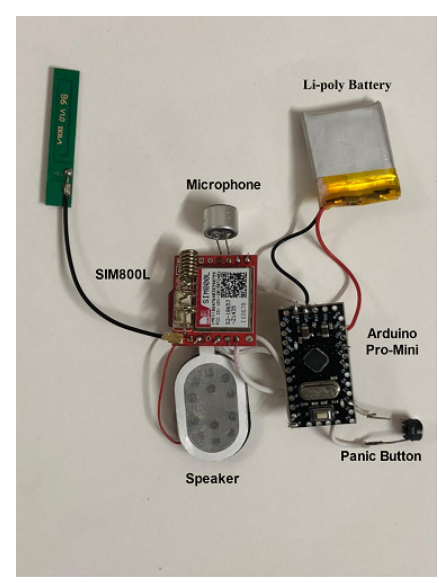

(a) Dissection View

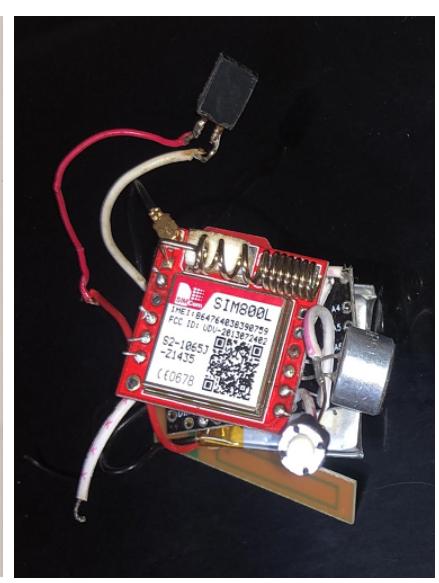

(b) Developed View.
Fig. 5. The Developed Form Factor of the Anti-Molestation Device.

\section{RESUlT}

In this section, we have discussed the methodology and result of our Anti-Molestation safety device. When a prey 
presses the panic button, the SIM800L module call to the "999" law enforcement agency number through the cell phone tower, and by GPRS technology, the device sends SMS with his/her current location and update it in the application server. The authority notifies the nearby police station to rescue the prey. Fig. $5 b$ illustrates the form factor of our device which is too small in size to carry anywhere easily. The device can send location continuously. If the law enforcement agency or police try to make a call to the device number, the device automatically discard the call and again send SMS with victim's current location. Here, Fig. 6a, 6b, and 6c shows the calling mechanism, location sending mechanism, and location traced in map of our safety device accordingly. Moreover, our device is so much power and cost efficient. The device runs a long with a single hour charge. Our safety device has shown a significant result among previous devices with the small form factor.

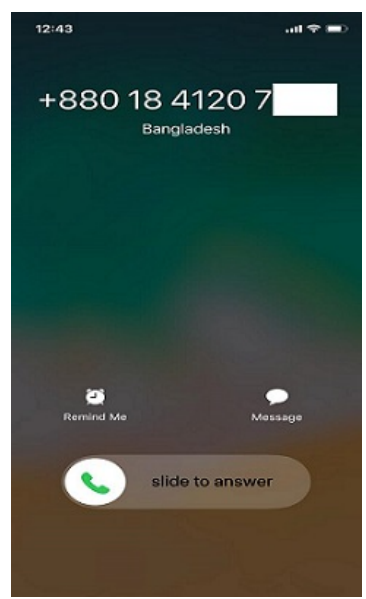

(a) Making Call.

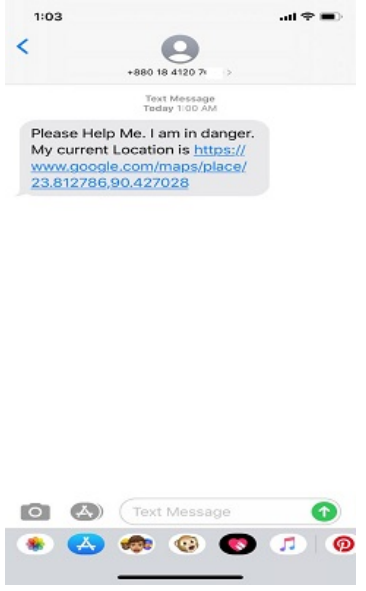

(b) Sending Location.

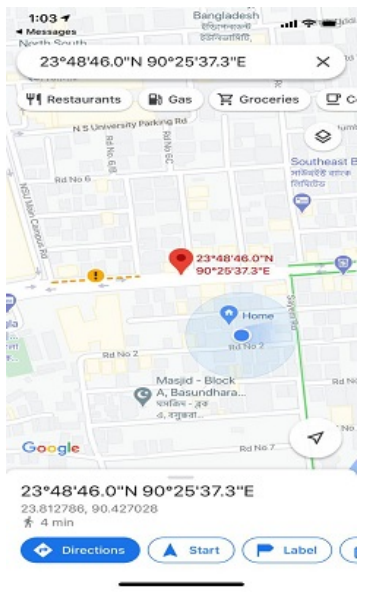

(c) Location in Map.

Fig. 6. The Qualitative Result of our Safety Device which can make a Call, send SMS with Location.

\section{CONCLUSION}

In this paper, we have proposed and illustrated our device, namely, "Anti-Molestation", an IoT-based safety device. This safety device aims to help women and children from being harassed in any situation. The device can directly inform law enforcement agencies to take legal actions against the culprits. Also, the device can send the victim's current position to the nearest police station to rescue the victim.

The device is so much user-friendly, and people of all levels can use it without any hassle at a low cost. Even though we have built a sophisticated system, we still have some limitations finding the victim's actual location. Location can be distorted up to 100 meters radius from the victim's position where he/she presses the button. We are trying to overcome this issue as soon as possible. Moreover, we will also give our product an aesthetic look so that we can take it to the mass production level quickly.

\section{REFERENCES}

[1] "Violence against women." https://www.who.int/en/news-room/factsheets/detail/violence-against-women (accessed Sep. 12, 2020) [online].

[2] "Rape Archives - Ain o Salish Kendra(ASK)." http://www.askbd.org/ask/category/hr-monitoring/violence-againstwomen-statistics/rape/ (accessed Sep. 12, 2020) [online].

[3] P. Brous, M. Janssen, and P. Herder, "The dual effects of the Internet of Things (IoT): A systematic review of the benefits and risks of IoT adoption by organizations," International Journal of Information Management, vol. 51. Elsevier Ltd, p. 101952, Apr. 01, 2020, DOI: 10.1016/j.ijinfomgt.2019.05.008.

[4] R. Ramachandiran, L. Dhanya, and M. Shalini, "A survey on women safety device using IoT," 2019 IEEE Int. Conf. Syst. Comput. Autom. Networking, ICSCAN, 2019, pp. 1-6, 2019, DOI: 10.1109/ICSCAN.2019.8878817.

[5] A. Z. M. Tahmidul Kabir, A. M. Mizan, and T. Tasneem, "Safety Solution for Women Using Smart Band and CWS App," pp. 566-569, 2020, DOI: 10.1109/ecti-con49241.2020.9158134.

[6] S. R. Mahmud, S. N. Tumpa, A. B. Islam, C. N. Ferdous, N. Paul, and T. T. Anannya, "BONITAA: A smart approach to support the female rape victims," 5th IEEE Reg. 10 Humanit. Technol. Conf. 2017, R10HTC, 2017, vol. 2018-January, pp. 730-733, 2018, DOI: 10.1109/R10HTC.2017.8289061.

[7] M. N. Islam et al., "SAFeBanD: A wearable device for the safety of women in Bangladesh," ACM Int. Conf. Proceeding Ser., pp. 76-83, 2018, DOI: 10.1145/3282353.3282363.

[8] S. Priyanka, Shivashankar, K. P. Roshini, S. P. Reddy, and K. Rakesh, "Design and implementation of SALVUS women safety device," 2018 3rd IEEE Int. Conf. Recent Trends Electron. Inf. Commun. Technol. RTEICT 2018 - Proc., pp. 2438-2442, 2018, DOI: 10.1109/RTEICT42901.2018.9012442.

[9] U. Rai, K. Miglani, A. Saha, B. Sahoo, and M. Vergin Raja Sarobin, "ReachOut Smart Safety Device," 2018 6th Ed. Int. Conf. Wirel. Networks Embed. Syst. WECON 2018 - Proc., pp. 131-134, 2018, DOI: 10.1109/WECON.2018.8782071.

[10] N. R. Sogi, P. Chatterjee, U. Nethra, and V. Suma, "SMARISA: A Raspberry Pi Based Smart Ring for Women Safety Using IoT,' Proc. Int. Conf. Inven. Res. Comput. Appl. ICIRCA, 2018, no. Icirca, pp. 451-454, 2018, DOI: 10.1109/ICIRCA.2018.8597424.

[11] S. K. Punjabi, S. Chaure, U. Ravale, and D. Reddy, "Smart Intelligent System for Women and Child Security," 2018 IEEE 9th Annu. Inf. Technol. Electron. Mob. Commun. Conf. IEMCON, 2018, no. Apr 9600, pp. 451-454, 2019, DOI: 10.1109/IEMCON.2018.8614929.

[12] T. Sen, A. Dutta, S. Singh, and V. N. Kumar, "ProTecht - Implementation of an IoT based 3 -Way Women Safety Device," Proc. 3rd Int. Conf. Electron. Commun. Aerosp. Technol. ICECA, 2019, pp. 1377-1384, 2019, DOI: 10.1109/ICECA.2019.8821913.

[13] K. Thamaraiselvi, S. Rinesh, L. Ramaparvathy, and V. Karthick, "Internet of Things (IOT) based smart band to ensure the security for women," Proc. 2nd Int. Conf. Smart Syst. Inven. Technol. ICSSIT 2019, no. Icssit, pp. 1093-1096, 2019, DOI: 10.1109/ICSSIT46314.2019.8987928. 
[14] M. R. Tejonidhi, Aishwarya, K. Chaithra, M. K. Dayana, and H. Nagamma, "IoT Based Smart Security Gadget for Women's Safety," 1st IEEE Int. Conf. Adv. Inf. Technol. ICAIT 2019 - Proc., pp. 348-352, 2019, DOI: 10.1109/ICAIT47043.2019.8987242.

[15] V. Sharma, Y. Tomar, and D. Vydeki, "Smart Shoe for Women Safety," 2019 IEEE 10th Int. Conf. Aware. Sci. Technol. iCAST 2019 - Proc., pp. 1-4, 2019, DOI: 10.1109/ICAwST.2019.8923204.

[16] N. Islam, M. R. Hossain, M. Anisuzzaman, A. J. M. Obaidullah, and S. S. Islam, "Design and Implementation of Women Auspice System by Utilizing GPS and GSM,” 2nd Int. Conf. Electr. Comput. Commun. Eng. ECCE, 2019, pp. 1-6, 2019, DOI: 10.1109/ECACE.2019.8679202.

[17] M. R. Ruman, J. K. Badhon and S. Saha, "Safety Assistant And Harassment Prevention For Women," 2019 5th International Conference on Advances in Electrical Engineering (ICAEE), Dhaka, Bangladesh, 2019, pp. 346-350, DOI: 10.1109/ICAEE48663.2019.8975648.

[18] V. Hyndavi, N. S. Nikhita, and S. Rakesh, "Smart Wearable Device for Women Safety Using IoT," no. Icces, pp. 459-463, 2020, DOI: 10.1109/icces48766.2020.9138047. 